\title{
Relation between Resilience and Life Satisfaction among Schizophrenic Patients
}

\author{
Amira Atef Mokhtar ${ }^{1}$, Mawaheb Mahmoud Zaki ${ }^{2}$, andMona Mohamed Abdel-Aziz Barakat ${ }^{3}$
}

(1) Clinical Instructor of Psychiatric \& Mental Health Nursing Faculty of Nursing- Benha University, (2) Assistant Professor of Psychiatric \& Mental Health Nursing Faculty of NursingBenha University (3) Assistant Professor of Psychiatric \& Mental Health Nursing Faculty of Nursing- Benha University.

\begin{abstract}
Background: Schizophrenia is a serious mental disorders characterized by sever cognitive impairments that affect patient's ability to cope with stress and therefore, lower resilience and life satisfaction. Aim of the study: Was to investigate the relation between resilience and life satisfaction among schizophrenic patients. Research design: A descriptive correlational design was used in this study. Setting: This study was conducted at Psychiatric and Mental Health Hospital in Benha City, Qalubia Governorate. Sample: A purposive sample consisted of 100 schizophrenic patients from the previous study setting. Tools: Three tools were used for data collection. Tool 1structured interview questionnaire was used to collect data about socio demographic and clinical characteristics of the studied sample. Tool (2):- The Connor-Davidson Resilience Scale (CD-RISC) to assess reference values for resilience in clinical samples. Tool (3):- Satisfaction with Life Scale was used to measure life satisfaction among the studied sample. Results: More than three quarters of the studied patients had low level of total resilience and the majority of the studied patients had low level of total life satisfaction and there was a highly statistically significant positive correlation between total resilience and total life satisfaction. Conclusion: In ability of schizophrenic patients to deal with stressors are prone to have low resilience that in turn lowers patient's life satisfaction.
\end{abstract} Recommendations: Psycho-educational training program should be developed to improve resilience and life satisfaction among schizophrenic patients.

Key words: Schizophrenia, Resilience, Life satisfaction.

\section{Introduction:}

Schizophrenia is a chronic brain disorder that affects up to $1 \%$ of the world population and characterized by three broad categories of symptoms: positive symptoms, negative symptoms, and cognitive symptoms (Goff, 2021). Schizophrenia considered one of the most costly worldwide disorders, being among the top 10 global causes of disability. For, instance, schizophrenia leads to severe functional and psychosocial impairments, challenges in community living and often disabling illness and meanwhile, has an adverse impact not only on the inflicted individual's health, quality of life and well- being but also on their surrounding environments (Marder \& Cannon, 2019).

Resilience is a dynamic process which encompasses positive adaptation within the context of significant adversity which affects ability to 'bounce back, or it is the person's ability to deal with stressors. Resilient individual has good mental health which confers considerable protection, contrary to schizophrenic patients, who have lower level of resilience due to cognitive impairments which affect $84 \%$ of individuals diagnosed with schizophrenia. Cognitive impairments and deprivation in brain structure hence, resilience mechanism among schizophrenic 
patients based on the brain structural connectivity (Benestad, 2020).

Resilience has considered a protective factor that foster a positive outcome among individuals facing adverse circumstances like schizophrenia and enhancing the effectiveness of psychotherapeutic treatments. Resilience improves compliance to medication, decrease relapse, suicidal attempt, promotes personal growth as well as cognitive survival. With the reciprocal influence of resilience and positive emotions among schizophrenic patients, satisfaction with life will be affected positively (Jaaskelainen et al., 2020).

Life satisfaction is an overall evaluation or appraisal of their life also it is cognitive component of subjective well-being (SWB) (Smith \& Konik., 2021). Personality traits mainly neuroticism is a strong factor that weakens life satisfaction. In addition to, severity of psychiatric symptoms mainly negative symptoms, social isolation, low selfesteem, sleep difficulties that affect majority of schizophrenic patients, educational status which is mainly distorted due to cognitive impairments (Boland et al., 2020). Also, marital status and unemployment, hence, all such factors decrease happiness, inhibit sense of well-being and life satisfaction among schizophrenic patient (Jennifer et al., 2020).

Basically psychiatric nurse has an important role toward schizophrenic patients in achieving functional recovery to develop meaningful life, social functioning, achieving good prognosis and good quality of life. For instance, targeting programs or interventions to improve resilience and life satisfaction such as stress coping, mindfulness, social support and positive emotions enhancing which increase life satisfaction through resilience building. To this end, internal locus of control, mental wellness, and effective community integration among schizophrenic patients will become a basic characteristic of patients (Lok \& Bademli, 2021).

\section{Significance of the study:}

Schizophrenia is severe mental disorder affecting $(0.28 \%) \quad 21$ million people worldwide. Schizophrenia life-span is shortened by an average of 28.5 years compared to that of the general population and associated with high excess mortality and patients are 2-3 times more likely to die early than the general population (World Health Oranization WHO, 2019). The National Institute of Mental Health (NIMH) estimated that the worldwide prevalence of schizophrenia is around 0.33 to $0.75 \%$ are non-institutionalized patients and estimated that between 0.25 and $0.64 \%$ of the U.S. population has schizophrenia (Cherry, 2020). While in Egypt by the end of 2019 the number of schizophrenic patients is estimated to be about (1 million) people (Ramy, 2019).

Several studies revealed low resilience level and in the majority schizophrenic patients, a study in USA proved the significant effect of resilience in reductions of both positive and negative symptoms, relapse and suicide rate with stabilization and increase in self-efficacy (Zizolfi et al., 2019). In addition, studied that proposed a severely decreased in life satisfaction among schizophrenic patients compared with healthy controls, and meanwhile, low life satisfaction worsen symptoms, decrease happiness, increase negative attitudes towards medication, increase rate of psychotic relapse and rehospitalization, increase suicidal attempts and functional recovery decreases (Pazoki et al., 2020). Hence, it was deemed necessary to evaluate resilience and life satisfaction among schizophrenic patients.

\section{Aim of the study:}

This study aimed to investigate the relation between resilience and life satisfaction among schizophrenic patients. 
Amira Atef Mokhtar, Mawaheb Mahmoud Zaki, and Mona Mohamed Abdel-Aziz Barakat.

Subject and Method:

\section{Research question:}

What is the relation between resilience and life satisfaction among schizophrenic patients?

\section{Research design:}

A descriptive correlational design was used in this study.

\section{Setting:}

The present study was conducted at the Psychiatric and Mental Health Hospital in Benha City, Qalubia Governorate, which is affiliated to General Secretariat of Mental Health in Egypt. It has 5 departments (4 males and 1 female); with a capacity of 220 beds and the total number of patients were 150 patients (120 male and 30 female). It works 24 hours a day, 7 days a week.

\section{Sample:}

\section{1- Sample size:}

The estimated sample size is 100 schizophrenic patients.

\section{2- Sample type:}

Purposive sample included in this study according to the following criteria:

1 - Both sexes.

2- Age ranges from 20-60 years.

3-Patient has insight and agrees to participate in the study.

Tools for data collection: Three tools were used in this study.

\section{Tool (I): A structured interviewing questionnaire:}

The questionnaire was developed by the researcher based on scientific review of literature to assess the following parts:

Part I:-Socio-demographic data: It consisted of 6 items to elicit data about the studied patient's as (age, sex, marital status, educational level, occupation and residence).

Part II: - Clinical data: It consisted of 8 items included (age at onset of the disease, number of previous hospitalization, duration of hospitalization and mode of admission, by whom in case of involuntary admission, family history of psychiatric disease and patient's relation to him).

\section{Tool (2):- The Connor-Davidson Resilience Scale (CD-RISC):}

The scale was originally developed by Connor \& Davidson, (2003) to establish reference values for resilience in general population and in clinical samples and how well one is equipped to bounce back after stressful events or trauma. The scale contains 25 items divided into 5 subscales covering the resilience characteristics and includes (personal competence consists of (7 items), control consists of (5 items), acceptance of change and secure relationships consist of (4 items), trust / tolerance/strengthening effects of stress consist of ( 7 items) and spiritual influences consist of ( 2 items). The response options ranged from (0) not true at all, (1) sometimes true and (2) true nearly all of the time.

\section{Scoring system:}

$\begin{array}{ll}\text { Low resilience }= & (<50 \%) . \\ \text { Moderate resilience }= & (50-70 \%) . \\ \text { High resilience }= & (>70 \%) .\end{array}$

\section{Tool (3):- Satisfaction with Life Scale:}

The scale was originally developed by ElDesouki, (1998). The scale designed to measure one's life satisfaction, the extent of the individual's enthusiasm for life and the true desire to live it. The scale consisted of 29-items divided into 6 subscales which includes Happiness (7 items), Sociality (4 items), Reassurance (6 items), Psychological stability (3 items), Social recognition (6 items) and Conviction (3 items). The response options ranged from (0) strongly disagree, (1) slightly agree and (2) strongly agree.

\section{Scoring system:}

Low life satisfaction $=\quad(<50 \%)$.

Moderate life satisfaction $=\quad(50-70 \%)$. 
High life satisfaction $=>70 \%$.

\section{Content validity of the tools:}

Arabic translation was done by researcher for Connor-Davidson Resilience Scale (CDRISC) and English translation for Satisfaction with Life Scale and tested for their translation. Content validity of tools was done by jury of 5 expertise (4 in Psychiatric Nursing Field from Benha, Menufia and Ainshams University and 1 in Psychiatric Medicine Field from Benha who checked the relevancy, comprehensiveness, clarity and applicability of the questions. According to their opinions modifications were done and the final form was developed.

\section{Reliability of the tools:}

Internal consistency of the tools was checked by test-retest reliability. Reliability for Connor-Davidson Resilience Scale was .89 and Satisfaction with Life Scale was .81.

\section{Ethical considerations:}

The objective and aim of the study were clarified by the researcher to every participant in the study, oral consent obtained from each patient before conducting the interview and they were assured for maintaining anonymity and confidentiality. The patients were informed that they have the right to participate in the study and the right to withdraw from the study at any time.

\section{A pilot study:}

After the tools were designed, they were tested through a pilot study, which was done before its application in the field work to check clarity and feasibility of the designed tools to be sure that it was understood and to estimate the time needed to complete its items. It was carried on a sample of $10 \%$ (10 schizophrenic patients) who were excluded later from the main study sample to assure stability of the results.

\section{Field work:-}

- The researcher started data collection by introducing herself to the patients.
- Brief description about the purpose of the study and the type of questionnaire required to fill was given to each patients.

- The sample was selected by interviewing 100 schizophrenic patients purposively that met the previous prescribed criteria and about 50 patients ( 9 female and 41 male) from total number of patients of hospital were excluded.

- Data collection was done by interviewing each patient individually and according to his condition such as aggressive, excited patient and patient who had modified electroconvulsive therapy unable to complete the assessments.

- The researcher started to collect data from patients, 5 patients/ day each interview lasted 30-45 min. Data collected from some patients on more than one day which depended on patient response and condition.

- The process of data collection took a period of 3 months from the first of August 2020 to the end of October 2020, 3 days week, from 10 A.M.: 12 P.M., 3 hours/ day, 3 days/week, 3 patients/ day and 1 patient/ hour.

\section{Statistical analysis :}

All data collected were organized, coded, computerized, tabulated and analyzed by using The Statistical Package for Social Science (SPSS programs version 20), which used frequencies and percentages for qualitative descriptive data, Chi-square was used for relation tests, mean and standard deviation was used for quantitative data and person correlation coefficient (r) was used for correlation analysis and degree of significance was identified. A highly statistical significant difference was considered if $\mathrm{p}$-value $<0.01$, statistical significant difference was considered if $\mathrm{p}$ value $<0.05$ and non-statistical significant 
Amira Atef Mokhtar, Mawaheb Mahmoud Zaki, and Mona Mohamed Abdel-Aziz Barakat.

difference was considered if $\mathrm{p}$-value $\mathrm{p}>$ 0.05 .

\section{Results:}

Table (1) Shows that, more than one third of the studied patients (39\%) their age ranged between $30-<40$ years, with mean age was $41.61 \pm 4.05$ year. As regards to sex, more than three quarters $(79 \%)$ of the studied patients were male, and more than half (55\%) were single. Also, less than half of the studied patients (42\%) had secondary education. Regarding to occupation, more than two thirds $(69 \%)$ were unemployed, moreover, more than one half of them $(54 \%)$ were residing in rural areas.

Table (2) Illustrates that, less than one third of the studied patients (30\%) their age at the onset of the disease was between $20-<25$ years, with mean age was $28.34 \pm 2.71$ years. Also, more than one third of them (38\%) admitted to hospital between periods 1- 3 times previously. Moreover, less than half of them $(44 \%)$ hospitalized from $5-<10$ years, with mean age was $12.70 \pm 0.93$. Likewise, all the studied patients (100\%) were admitted to the hospital in an involuntary manner, more than three quarters $(78 \%)$ were admitted with their families. Also, (9\%) of the studied patients had family history of psychiatric disorders, and (100\%) suffered from schizophrenia respectively, and more than half of them $(55.6 \%)$ were Father / Mother that have schizophrenia.
Figure (1) Shows that, more than three quarters of the studied patients $(76 \%)$ had low level of total resilience.

Figure (2) Shows that, the majority of the studied patients $(80 \%)$ had low level of total life satisfaction. Also, less than one fifths of them $(15 \%)$ had moderate level. While less than one fifth of them (5\%) had high level.

Table (3) Demonstrate that, there was statistically significant relation between total life satisfaction of the studied patients and their socio-demographic characteristics as age, marital status and education level at $\mathrm{p}$ value $=<0.05$

Table (4) Reveals that, there was a highly statistically significant relation between total resilience of the studied patients and their number of previous hospitalizations and duration of hospitalization at $\mathrm{p}$-value $=<$ 0.01 . Also, there was statistically significant relation with their age at the onset of the disease at $\mathrm{p}$-value $=<0.05$ ).

Table (5) Shows that, there was a highly statistically significant positive correlation between total resilience of the studied patients and their total life satisfaction at $p$-value $=<$ 0.01 . 
Table (1): Distribution of the studied patients according to their socio-demographic data $(\mathbf{n}=\mathbf{1 0 0})$.

\begin{tabular}{|c|c|c|}
\hline Socio-demographic characteristics & No & $\%$ \\
\hline \multicolumn{3}{|l|}{ Age (year) } \\
\hline - $20-<30$ & 9 & 9 \\
\hline - $30-<40$ & 39 & 39 \\
\hline - $40-<50$ & 35 & 35 \\
\hline - $50-\leq 60$ & 17 & 17 \\
\hline \multicolumn{3}{|l|}{ Mean \pm SD } \\
\hline \multicolumn{3}{|l|}{ Sex } \\
\hline - Male & 79 & 79 \\
\hline - Female & 21 & 21 \\
\hline \multicolumn{3}{|l|}{ Marital status } \\
\hline - Single & 55 & 55 \\
\hline - Married & 20 & 20 \\
\hline - Divorced & 21 & 21 \\
\hline - Separate & 2 & 2 \\
\hline - Widowed & 2 & 2 \\
\hline \multicolumn{3}{|l|}{ Educational level } \\
\hline - Illiterate & 12 & 12 \\
\hline - Read \& write & 11 & 11 \\
\hline - Primary education & 16 & 16 \\
\hline - Secondary education & 42 & 42 \\
\hline - University degree & 19 & 19 \\
\hline \multicolumn{3}{|l|}{ Occupation } \\
\hline - Employed & 31 & 31 \\
\hline - Unemployed & 69 & 69 \\
\hline \multicolumn{3}{|l|}{ Residence } \\
\hline - Rural & 54 & 54 \\
\hline - Urban & 46 & 46 \\
\hline
\end{tabular}


Amira Atef Mokhtar, Mawaheb Mahmoud Zaki, and Mona Mohamed Abdel-Aziz Barakat.

Table (2): Distribution of the studied patients according to their clinical data $(n=100)$.

\begin{tabular}{|c|c|c|}
\hline Clinical data & No & $\%$ \\
\hline \multicolumn{3}{|l|}{ Age of onset of the disease (years) } \\
\hline - $15-<20$ Years & 8 & 8 \\
\hline - $20-<25 \quad$ Years & 30 & 30 \\
\hline - 25-<30 Years & 17 & 17 \\
\hline - $30-<35 \quad$ Years & 19 & 19 \\
\hline - $\geq 35 \quad$ Years & 26 & 26 \\
\hline \multicolumn{3}{|l|}{ Mean \pm SD } \\
\hline \multicolumn{3}{|l|}{ Number of previous hospitalizations } \\
\hline - From 1- 3 times & 38 & 38 \\
\hline - From 4- 6 times & 34 & 34 \\
\hline - From 7 times and above & 28 & 28 \\
\hline \multicolumn{3}{|l|}{ Duration of hospitalization (years) } \\
\hline - $5-<10 \quad$ Years & 44 & 44 \\
\hline - $10-<15$ Years & 26 & 26 \\
\hline - $15-<20$ Years & 12 & 12 \\
\hline - $\geq 20 \quad$ Years & 18 & 18 \\
\hline \multicolumn{3}{|c|}{$12.70 \pm 0.93$} \\
\hline \multicolumn{3}{|l|}{ Mode of admission } \\
\hline - Voluntary & 0 & 0.0 \\
\hline - Involuntary & 100 & 100 \\
\hline \multicolumn{3}{|c|}{ In case of Involuntary admission, is it through } \\
\hline - Family & 78 & 78 \\
\hline - Transfer from another hospital & 16 & 16 \\
\hline - Police & 3 & 3 \\
\hline - Neighbors & 3 & 3 \\
\hline \multicolumn{3}{|l|}{ Family history of psychiatric disorders } \\
\hline - Yes & 9 & 9 \\
\hline - No & 91 & 91 \\
\hline \multicolumn{3}{|l|}{ If yes, what is the disease? $(n=9)$} \\
\hline - Schizophrenia & 9 & 100 \\
\hline - Anxiety disorder & 0 & 0.0 \\
\hline - Depression & 0 & 0.0 \\
\hline - Bipolar disorder & 0 & 0.0 \\
\hline \multicolumn{3}{|c|}{ The relationship between you and the patient is $(n=9)$} \\
\hline - Father / Mother & 5 & 55.6 \\
\hline - Brother / Sister & 3 & 33.3 \\
\hline - Uncle / Aunt & 0 & 0.0 \\
\hline - Grandfather / Grandmother & 1 & 11.1 \\
\hline
\end{tabular}




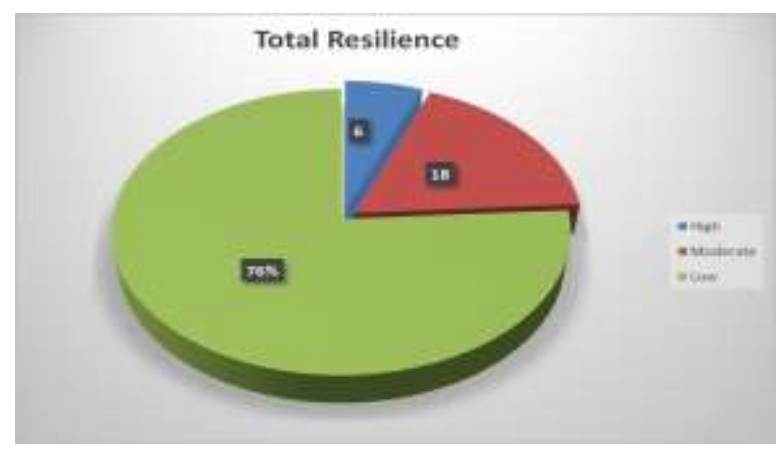

Figure (1): Distribution of the studied patients according to their total level of resilience $(\mathbf{n}=\mathbf{1 0 0})$.

\section{Total life satisfaction}

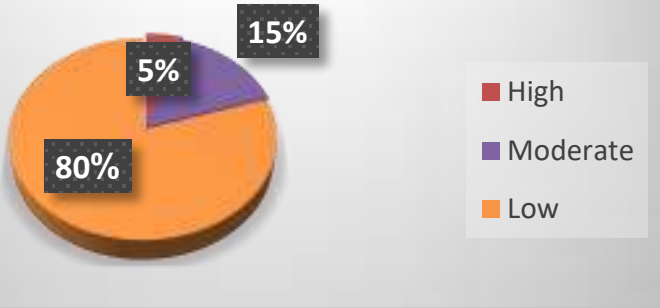

Figure (2): Distribution of the studied patients according to their total level of life satisfaction $(\mathbf{n}=\mathbf{1 0 0})$.

Table (3): Relationship between socio-demographic characteristics of the studied patients and their total life satisfaction $(n=100)$.

\begin{tabular}{|c|c|c|c|c|c|c|c|c|c|}
\hline \multirow{2}{*}{\multicolumn{2}{|c|}{ Socio-demographic characteristics }} & \multicolumn{6}{|c|}{ Total life satisfaction } & \multirow{3}{*}{$\mathbf{X} 2$} & \multirow{3}{*}{$\begin{array}{c}\text { P- } \\
\text { Value }\end{array}$} \\
\hline & & \multicolumn{2}{|c|}{$\begin{array}{l}\text { High } \\
(\mathbf{n}=5)\end{array}$} & \multicolumn{2}{|c|}{$\begin{array}{c}\text { Moderate } \\
(\mathbf{n}=\mathbf{1 5}) \\
\end{array}$} & \multicolumn{2}{|c|}{ Low $(n=80)$} & & \\
\hline & & No & $\%$ & No & $\%$ & No & $\%$ & & \\
\hline \multirow{4}{*}{ Age (year) } & $20-<30$ & 0 & 0.0 & 1 & 6.7 & 8 & 10 & \multirow{4}{*}{12.47} & \multirow{4}{*}{$.045^{*}$} \\
\hline & $30-<40$ & 0 & 0.0 & 2 & 13.3 & 37 & 46.3 & & \\
\hline & $40-<50$ & 3 & 60 & 9 & 60 & 23 & 28.7 & & \\
\hline & $50-\leq 60$ & 2 & 40 & 3 & 20 & 12 & 15 & & \\
\hline \multirow[t]{2}{*}{ Sex } & Male & 5 & 100 & 12 & 80 & 62 & 77.5 & \multirow[t]{2}{*}{1.447} & \multirow[t]{2}{*}{.485} \\
\hline & Female & 0 & 0.0 & 3 & 20 & 18 & 22.5 & & \\
\hline \multirow[t]{5}{*}{ Marital status } & Single & 2 & 40 & 7 & 46.7 & 40 & 50 & \multirow{5}{*}{12.09} & \multirow{5}{*}{$.027 *$} \\
\hline & Married & 3 & 60 & 6 & 40 & 13 & 16.3 & & \\
\hline & Divorced & 0 & 0.0 & 2 & 13.3 & 19 & 23.7 & & \\
\hline & Separate & 0 & 0.0 & 0 & 0.0 & 2 & 2.5 & & \\
\hline & Widowed & 0 & 0.0 & 0 & 0.0 & 2 & 2.5 & & \\
\hline \multirow{5}{*}{ Educational level } & Illiterate & 0 & 0.0 & 2 & 23.3 & 10 & 12.5 & \multirow{5}{*}{11.434} & \multirow{5}{*}{$.038 *$} \\
\hline & Read \& write & 0 & 0.0 & 1 & 6.7 & 10 & 12.5 & & \\
\hline & Primary & 0 & 0.0 & 2 & 13.3 & 14 & 17.5 & & \\
\hline & Secondary & 1 & 20 & 8 & 53.4 & 33 & 41.3 & & \\
\hline & University & 4 & 80 & 2 & 13.3 & 13 & 16.3 & & \\
\hline \multirow[t]{2}{*}{ Occupation } & Work & 1 & 20 & 6 & 40 & 24 & 30 & \multirow[t]{2}{*}{.888} & \multirow[t]{2}{*}{.641} \\
\hline & Don't work & 4 & 80 & 9 & 60 & 56 & 70 & & \\
\hline \multirow[t]{2}{*}{ Residence } & Rural & 2 & 40 & 7 & 46.7 & 45 & 56.3 & \multirow[t]{2}{*}{.822} & \multirow[t]{2}{*}{.643} \\
\hline & Urban & 3 & 60 & 8 & 53.3 & 35 & 43.8 & & \\
\hline
\end{tabular}

*significant at $\mathrm{p}<0.05$. 
Amira Atef Mokhtar, Mawaheb Mahmoud Zaki, and Mona Mohamed Abdel-Aziz Barakat.

Table (4): Relation between the clinical data of the studied patients and their total resilience ( $n=100)$.

\begin{tabular}{|c|c|c|c|c|c|c|c|c|c|}
\hline \multirow{3}{*}{\multicolumn{2}{|c|}{ Clinical data }} & \multicolumn{6}{|c|}{ Total Resilience } & \multirow{3}{*}{$\mathbf{X} 2$} & \multirow{3}{*}{$\begin{array}{c}\text { P- } \\
\text { Value }\end{array}$} \\
\hline & & \multicolumn{2}{|c|}{$\begin{array}{l}\text { High } \\
(\mathrm{n}=6)\end{array}$} & \multicolumn{2}{|c|}{$\begin{array}{l}\text { Moderate } \\
(\mathbf{n}=18)\end{array}$} & \multicolumn{2}{|c|}{$\begin{array}{c}\text { Low } \\
(n=76)\end{array}$} & & \\
\hline & & No & $\%$ & No & $\%$ & No & $\%$ & & \\
\hline \multirow{5}{*}{$\begin{array}{l}\text { Age at the onset of } \\
\text { the disease (years) }\end{array}$} & $15-<20$ & 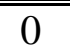 & 0.0 & 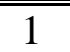 & 6.7 & 8 & 10 & \multirow{5}{*}{12.47} & \multirow{5}{*}{$.045^{*}$} \\
\hline & $20-<25$ & 0 & 0.0 & 2 & 13.3 & 37 & 46.3 & & \\
\hline & $25-<30$ & 3 & 60 & 9 & 60 & 23 & 28.7 & & \\
\hline & $30-<35$ & 2 & 40 & 3 & 20 & 12 & 15 & & \\
\hline & $\geq 35$ & 0 & 0.0 & 1 & 6.7 & 8 & 10 & & \\
\hline \multirow{3}{*}{$\begin{array}{l}\text { Number of previous } \\
\text { hospitalizations }\end{array}$} & From 1- 3 times & 4 & 66.7 & 6 & 33.3 & 28 & 36.8 & \multirow{3}{*}{16.740} & \multirow{3}{*}{$.002 * *$} \\
\hline & From 4- 6 times & 2 & 33.3 & 2 & 11.1 & 30 & 39.4 & & \\
\hline & $\begin{array}{l}\text { From } 7 \text { times and } \\
\text { above }\end{array}$ & 0 & 0.0 & 10 & 55.6 & 18 & 23.7 & & \\
\hline \multirow{4}{*}{$\begin{array}{l}\text { Duration of } \\
\text { hospitalization } \\
\text { (years) }\end{array}$} & $5-<10$ & 2 & 33.3 & 7 & 38.9 & 35 & 46.1 & \multirow{4}{*}{12.811} & \multirow{4}{*}{$.008 * *$} \\
\hline & $10-<15$ & 0 & 0.0 & 3 & 16.7 & 23 & 30.3 & & \\
\hline & $15-<20$ & 3 & 50 & 3 & 16.7 & 6 & 7.9 & & \\
\hline & $\geq 20$ & 1 & 16.7 & 5 & 27.7 & 12 & 15.8 & & \\
\hline $\begin{array}{l}\text { Family history of } \\
\text { psychiatric } \\
\text { disorders }\end{array}$ & Yes & 1 & 16.7 & 1 & 5.6 & 7 & 9.2 & 6.950 & .706 \\
\hline
\end{tabular}

*significant at $\mathrm{p}<0.05 . * *$ highly significant at $\mathrm{p}<0.01$.

Table (5): Correlation between total resilience and life satisfaction among the studied patients.

\begin{tabular}{|c|c|c|}
\hline \multirow{2}{*}{ Scales } & \multicolumn{2}{|c|}{ Total Life Satisfaction } \\
\cline { 2 - 3 } & $\mathrm{r}$ & $\mathrm{p}$-value \\
\hline Total Resilience & 0.436 & $.000^{* *}$ \\
\hline
\end{tabular}

\section{Discussion:}

Data emerging from the study showed that, regarding socio-demographic characteristics of the studied patients, the result revealed that, more than one third of the studied patient's age ranged between 30 to less than 40 years, with mean age was $41.61 \pm 4.05$ year. This may be due to schizophrenia disease typically emerges in late adolescence and early adulthood. This result was in agreement with a study done by Cetin \& Aylaz, (2020) who found that, more than one third of the studied patients their age between 30 to 40 years.

In the other hand, these this result finding was in disagreement with a study carried out by Barranha et al., (2020) who found that, only one quarter of the patients belonged to 30 to 40 year age group and the majority aged between 40 to 50 years. Also this study was contradicted with a study done by Okasha et 
al., (2020) who found that, half of the studied patients their age ranged from 20 to less than 30 years.

As regards to sex, the current study revealed that, males are exceeding than females, as more than three quarters of the studied patients were male. This may be due to the underlying protective effect of women estrogen. This result was in the same line with a study done by Awaad et al., (2020); \& Philip et al., (2020) who mentioned that more than three quarters of the studied patients were male.

Concerning to marital status, the result of this study revealed that more than half of patients were single. This related to the debilitating nature or impact of the illness on the overall functioning of the individual which make patients face difficulties to keep up marital relations or may be a reason for divorce or separation as majority of them were single. This result was in the same line with a study done by Cetin \& Aylaz, (2020); \& Abdeen et al., (2019) who found that, more than half of the studied patients were single. This study was contradicted with a study done by Jaberi et al (2020) who found that three quarter of the studied sample was married

Regarding to age at onset of disease, the result of this study illustrates that, less than one third of the studied patients their age at the onset of the disease was ranged from $20-<25$ years. This result related to that age at onset of schizophrenia is typically between late adolescence and early adulthood. This result was contradicted with a study done by Okasha et al., (2020) who found that, less than one third of the studied patients their age at the onset of the disease were at $\geq 35$ years.

With regard to number of previous hospitalization, the result of this study illustrates that more than one third of patients admitted to hospital between periods 1- 3 times previously. This may be due to noncompliance to medication regimens that can lead to relapse and re-hospitalization. The result of this study come in line with a study done by Abdel-Rahman \& Berma, (2017) who found that, more than one third of the studied patients admitted to hospital between period 1- 3 times previously. By contrast, this study was in consistent with a study done by Abd-Elmonem et al., (2019) who revealed that the majority of the studied patients admitted from 1-3 times.

Concerning to duration of hospitalization, this result revealed that less than half of the studied patients hospitalized from $5-<10$ years. From view point of researcher this is related to frequency of admission of the patients to the hospital and due to the fact that schizophrenia is chronic psychiatric illness and progressive and disabling condition. This study came in line with a study done by Rabei et al., (2019) who found that, less than half of the studied patients hospitalized from $5-<10$ years.

In relation to total level of resilience among schizophrenic patients, these results revealed that, more than three quarters of the studied patients had low level of total resilience. This may be primary due to neurocognitive dysfunction decreasing the patient's response to psychosocial stress and adverse events and stress among such patients arises from many factors such as hospitalization, lack of behavioral and social skills, lack of empathy and support from surroundings, impaired interpersonal relationships, poor role functioning and stigma.

This result came in agreement with a study done by Abdel-Rahman et al., (2020) 
who stated that, resilience is generally low in schizophrenic patients due to the severity of psychotic symptoms and stress is highly related to schizophrenia development and prognosis. In addition to, Wambua et al., (2020) reported lower levels of resilience among schizophrenic patients due to negative symptoms and this cause poorer psychosocial functioning.

Concerning to total level of life satisfaction among the studied patients, the result of this study revealed that, the majority of the studied patients have low level of total life satisfaction. This may occurred as an effect of depressive symptoms which worsen life satisfaction and also, feeling of isolation. This result agreed with a study done by Seo \& Lim., (2019) who studied optimism and life satisfaction in persons with schizophrenia, his study showed that, the majority of patients have lower levels of life satisfaction than healthy controls due to stress and decreased optimism.

Regarding the statistically significant relation between total life satisfaction of the studied patients and their age, from view point of researcher this may due to more than one third of the patient age were between $30-<40$ year and patients at this age feel dissatisfaction and incompletion and also, this age of marriage and work and more than half of the studied patients were single and less than half of them were secondary education so, patients feel stressed, unhappy and focus on negative aspects of life which decrease life satisfaction.

Concerning to the statistically significant relation between total life satisfaction and marital status, this may be related to marriage as it has a role in improving life satisfaction through achieving marital satisfaction but, more than half of patients were single so have low level of life satisfaction. This was also supported by Laxhman et al., (2017) who studied satisfaction with sex life among patients with schizophrenia and reported that patients experience their sex life as an area of particular dissatisfaction.

Regarding to the highly statistically significant relation between total resilience of the studied patients and their number of previous hospitalizations and duration of hospitalization at p-value $<0.01$, this related to, hospitalization which cause exacerbated feelings of isolation. On the other hand patients were involuntary admitted and so on stress increased which result in decreasing resilience. This result came in line with a study done by Senormanci et al., (2020) who reported a significant relation between duration of hospitalization and resilience level and hospitalization may cause the resilience of patients with psychiatric disorders to be weaker, which is not conducive to recovery.

Similarly, there is a statistically significant relation between total resilience of the studied patients and their age at the onset of the disease at $p$-value $<0.05$. This related to that, less than one thirds their age at onset of disease ranged from $20-<25$ years thus reflecting less certainty about the nature of schizophrenia-like symptoms but, still have cognitive impairments that cause low resilience. This result came in agreement with a study done by Wei et al., (2020) who reported a significant relation between resilience level and age at the onset of the disease of patients. By contrast, Deng et al., (2018) reported no significant relation between resilience and age at onset of disease of the patients.

In accordance to the correlation between total resilience and life satisfaction among the studied patients, there was a highly 
statistically significant positive correlation between total resilience of the studied patients and their total life satisfaction at p-value < 0.01. From view point of researcher this mainly caused by the disruption of overall organization of brain networks and this cognitive dysfunction cause responses to stressors inevitably come down hence, maladaptation occur which result in low resilience and concurrently, low resilience decreases psychological well-being and satisfaction with life.

Low levels of resilience cause patient with schizophrenia unable take advantage of their positive emotions, or survive their adverse experiences and therefore, not have an extraordinary ability to adapt to significant change or deeply believes that life is meaningful, which reflected on and affect positively their perception of life satisfaction. This result was consistent with Zaki et al., (2019) who studied quality of life and resilience among patients with schizophrenia and revealed a highly statistically significant positive correlation between quality of life and resilience among patients with schizophrenia.

This result was meanwhile resembles to a study done by Rozya et al., (2019) who studied the strengths in patients with schizophrenia and healthy people and reported that patients with schizophrenia had low gratitude, spirituality and control which affect their life satisfaction negatively. This beyond, Kim \& Jang., (2019) who stated a highly statistically significant positive correlation between self-esteem, quality of life and resilience in people with schizophrenia.

\section{Conclusion:}

Findings confirmed that, resilience and life satisfaction seem to be related with each other. The present study revealed that, more than three quarters of the studied patients had low level of total resilience and the majority of the studied patients had low level of total life satisfaction. Patients reported low level of and life satisfaction, are largely answered resilience the research question concerning the levels of resilience and life satisfaction among schizophrenic patients. Also, it is observed that, there was a highly statistically significant positive correlation between total resilience and total life satisfaction, which means that, patients who had low score of resilience are more likely to have low life satisfaction and this answered the research question about the relation between resilience and life satisfaction among schizophrenic patients.

\section{Recommendations:}

- Psycho-educational training program to improve resilience and life satisfaction.

- Enhancing resilience through mindfulness program, identifying strengths, and selfefficacy, sense of coherence, resourcefulness and building a positive identity to improve resilience and life satisfaction among schizophrenic patients.

- Targeting psychotherapy approaches, especially religion-based therapies as complementary therapies alongside medical treatments to improve resilience and overall life satisfaction. 


\section{References:}

Abd-Elmonem, R., Abd-Elfatah, S., \& Mohammed, A. (2019). Effect of social competence program on self-esteem and assertiveness among schizophrenic patients. Minia Scientific Nursing Journal. 4, (1), pp 5060.

\begin{abstract}
Abdel-Rahman, A., Ramadan, M., AbdelMaksoud, A., \& Ibrahim, A. (2020). Relationship between psychological resilience and frequency of relapse and re-hospitalization in a sample of schizophrenic patients visiting Port-Said mental health and addiction treatment hospital. International Journal of Medical Arts. 2, (1), pp 179-184.
\end{abstract}

Abdel- Rahman, S., \& Berma, A. (2017). Patterns used by schizophrenic patients to cope with auditory hallucination. Port Said Scientific Journal of Nursing. 4, (1), pp 18-39.

Awaad, M., Ibrahim, N., Naguib, R., Khalil, S., Elhabiby, M., \&Mohamed, Z. (2020). Role of traditional healers in the pathway to care of patients with schizophrenia in Egypt. International Journal of Social Psychiatry. 66, (4), pp 382-388.

Barranha, R., Teixeira1, T., Quarenta, J., \& Doellinger, O. (2020). Living conditions of patients with schizophrenia spectrum disorders in the region of 'Tâmegae Sousa' (Portugal). International Journal of Social Psychiatry. 2, (1), pp 1-7.

Benestad, T. (2020). Full recovery and resilience in first episode schizophrenia: A longitudinal multilevel study. Thesis at the department of psychology university of Oslo. Pp43-45. Available at http://www.duo.uio.no. Retrieved on 12, February, 2021.
Boland, C., Gallagher, P. \& Clarke, M. (2020). Sleep disturbance: a potential target to improve symptoms and quality of life in those living with psychosis. Irish Journal of Psychological Medicine. 37, (1), pp 12-18.

Çetin, N., \& Aylaz, R. (2020). The relationship of mindfulness-based psycho-education provided to schizophrenic patients with their sociodemographic characteristics in increasing insight. Perspectives in Psychiatric Care. 56, (2), pp 1-12.

Cherry, K. (2020). How prevalent is schizophrenia? Available at: https://www. verywellmind.com/prevalence-of-schizophrenia4845619. Reterived on 16, February, 2020.

Connor, K. \& Davidson, J. (2003): Development of a new resilience scale: The Connor-Davidson resilience scale (CD-RISC): Depress Anxiety. 18 (2), pp 76-82.

Deng, M., Pan, Y., Zhou, L., \& Chen, X. (2018). Resilience and cognitive function in patients with schizophrenia and bipolar disorder, and healthy controls: Front Psychiatry. 9, pp 279. El-Desouki, M. (1998). Guide of instructions: The satisfaction with life scale. Al-Nahda egyptian house, Cairo, first edition, p 2.

Goff, D. (2021). The pharmacologic treatment of schizophrenia- 2021. JAMA Psychiatry. 325, (2), pp 175-176.

Jaaskelainen, E., Miettunen, J., \& Ahmed, A. (2020). Have we got better in making our schizophrenia patients better? Frontiers in Psychiatry. 11, (1), pp 1-3.

Jaberi, N., Faramarzi, E., Farahbakhsh, M., Ostadarahimi, A., Jafarabadi, M., \& Fakhari, A. (2020). Prevalence of metabolic syndrome in schizophrenia patients treated with antipsychotic medications. Caspian Journal of Internal Medicine.11, (3), pp 310-314. 
Jennifer, S., John, W., Michael, F., Emre, U., \& Fong, C. (2020). Psychiatric symptoms, psychosocial factors, and life satisfaction among persons with serious mental illness: A path analysis. The Journal of Nervous and Mental Disease. 208, (8), pp, 600-607.

Kim, E. \& Jang, M. (2019). The mediating effects of self-esteem and resilience on the relationship between internalized stigma and quality of life in people with schizophrenia: Asian Nursing Research. 13(4), pp 257-263.

Laxhmana, N., Greenberg, L., \&Priebe, S. (2017). Satisfaction with sex life among patients with schizophrenia. Schizophrenia Research. 190, pp 63-67.

Lok, N., \& Bademli, K. (2021). The Relationship between the perceived social support and psychological resilience in caregivers of patients with schizophrenia. Community Mental Health Journal. 57, (2), pp 387-391.

Marder, S., \& Cannon, T. (2019). Schizophrenia. The New England Journal of Medicine. 381, (18), pp. 1753-1761.

Okasha, T., Hussein, H., Shorub, E., Nagi, H., Moustafa, A., \& El-Serafi, D. (2020). Cognitive dysfunction among inpatients and outpatients with schizophrenia: relationship to positive and negative symptoms. Middle East Current Psychiatry. 27, 58, pp118-125.

Okasha, T., Sabry, W., Hashim, M., Abdeen, M., \& Abdelhamid, A. (2020). Vitamin D serum level in major depressive disorder and schizophrenia. Middle East Current Psychiatry. 27, (34), pp 320-328.

Pazoki, R., Lin, B., van-Eijk, K., Schijven, D., Zwarte, S., Guloksuz, S., \& Luykx, J. (2020). Phenome-wide and genome-wide analyses of quality of life in schizophrenia. Cambridge University Press. 3, (1), pp 13- 14.

Philip, B., Cherian, A., Shankar, R., \& Rajaram, P. (2020). Severity of disability in persons with schizophrenia and its socio- demographic and illness correlates. Indian Journal of Social Psychiatry. 36, (1), pp 80-86.

Rabei, S., ElBoraie, H., Elsaadouni, N., \& Elhadidy, M. (2019). Schizophrenia symptom dimensions in correlation to patients' demographic and clinical characteristics. Egyptian Journal of Psychiatry. 40, (3), pp 137140.

Ramy, H. (2019). Former "mental health" secretary: 5 million Egyptians suffer from depression. Available at: https://.masrawy.com/news/news_egypt/details/2 019/1/ 30/1505535/. Retrieved on 14, April, 2020.

Rozya, P., Sawicka, M., Żochowska, A., \& Bronowski, P. (2019). Strengths in patients with schizophrenia and healthy people - similarities and differences Psychiatr. Pol Journal. 53, (1), pp 93-104.

Senormanci, G.,

Korkmaz, N., Senormanc, S., Ugur, S., Topsac, M., \& Gültekin, O. (2020). Effects of exercise on resilience, insight and functionality in patients with chronic schizophrenia in a psychiatric nursing home setting: A randomized controlled trial. Issues in Mental Health Nursing. 41, (1), pp111-112.

Seo, M., \& Lim, Y. (2019). Optimism and life satisfaction in persons with schizophrenia living in the community. International Journal of Social Psychiatry. 65, (5), pp 615-620.

Smith, C., \& \& Konik, J. (2021). Who is satisfied with life? Personality, cognitive flexibility, and life satisfaction. Current Psychology. 40. (1), pp 1-8.

Wambua, N., Kilian, S., Ntlantsana, V., \& Chiliza, B. (2020). The association between resilience and psychosocial functioning in schizophrenia: A systematic review and metaanalysis. Psychiatry research. 293, 1- 6. 
Amira Atef Mokhtar, Mawaheb Mahmoud Zaki, and Mona Mohamed Abdel-Aziz Barakat.

Wei, Q., Zhao, L., Zou, Y., Wang, J., Qiu, Y., Niu, M., \& Kang, Z. (2020): The role of altered brain structural connectivity in resilience, vulnerability, and disease expression to schizophrenia. Progress in NeuroPsychopharmacology and Biological Psychiatry. 101, (6), pp 318- 325.

World Health Organization (Who), (2019). Schizophrenia. Available at: http://www.who.int/ ar/news-room/fact-sheets/detail/schizophrenia. Retrieved on 2, March, 2020.
Zaki, R., \& Abd El-Saliheen, F. (2019). Quality of life and resilience among patients with schizophrenia. Journal of Nursing and Health Science (IOSR-JNHS). 8, (4), pp 49-58.

Zizolfi, D., Poloni, N., Caselli, I., Ielmini, M., Lucca, G., Diurni, M., \& Callegari, C. (2019). Resilience and recovery style: a retrospective study on associations among personal resources, symptoms, neurocognition, quality of life and psychosocial functioning in psychotic patients. Psychology Research and Behavior Management. 12, pp 385-395. 


\section{العلاقه بين المرونه و الرضا عن الحياه بين مرضى الفصام}

$$
\text { أميره عاطف مختار - مواهب محود ذكى - منى محم عبدالعزيز }
$$

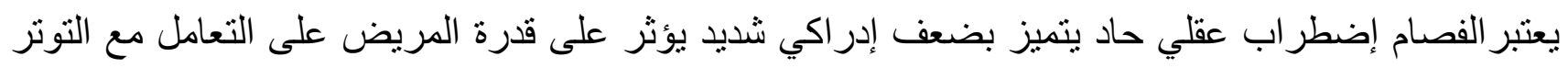

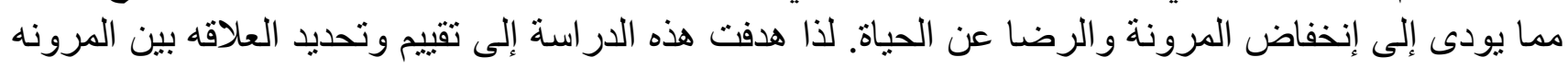

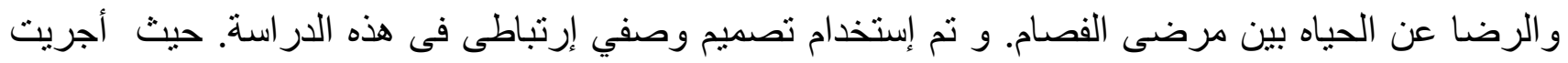

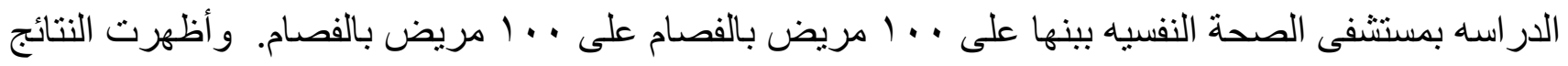

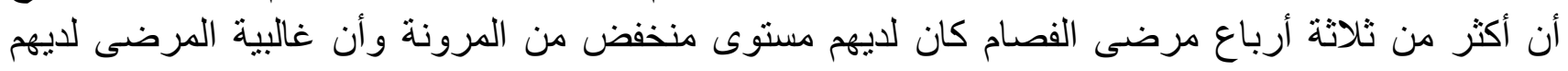

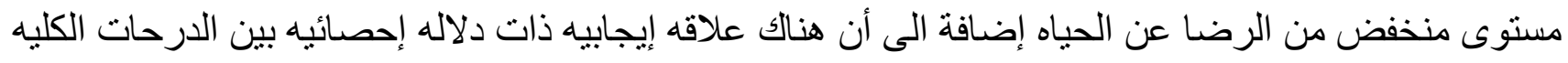

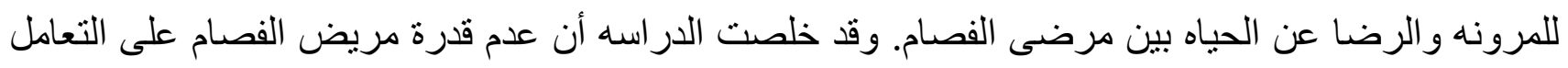

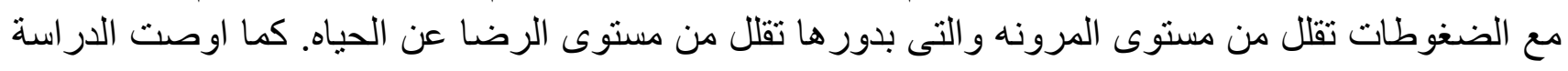

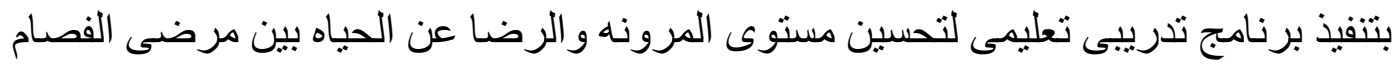

